\title{
Recurrent extraneural sonic hedgehog medulloblastoma exhibiting sustained response to vismodegib and temozolomide monotherapies and inter-metastatic molecular heterogeneity at progression
}

\author{
Gregorio J. Petrirena ${ }^{1}$, Julien Masliah-Planchon ${ }^{2,3}$, Quentin Sala ${ }^{4}$, Bertrand \\ Pourroy $^{5}$, Didier Frappaz ${ }^{6}$, Emeline Tabouret $^{1,7}$, Thomas Graillon ${ }^{8}$, Jean-Claude \\ Gentet $^{9}$, Olivier Delattre ${ }^{2,3}$, Olivier Chinot $^{1,7}$ and Laetitia Padovani ${ }^{10}$ \\ ${ }^{1}$ Service de Neuro-Oncologie, Hôpital La Timone, Assistance Publique-Hôpitaux de Marseille, Marseille, France \\ ${ }^{2}$ Unité de Génétique Somatique, Département de Génétique Oncologique, Institut Curie, Paris, France \\ ${ }^{3}$ INSERM_U830, Institut Curie, Paris, France \\ ${ }^{4}$ Service de Médecine Nucléaire, Hôpital Nord, Assistance Publique-Hôpitaux de Marseille, Marseille, France \\ ${ }^{5}$ Unité Oncopharma, Service Pharmacie, Hôpital La Timone, Assistance Publique-Hôpitaux de Marseille, Marseille, France \\ ${ }^{6}$ Service de Neuro-Oncologie Pédiatrique et Adulte, Centre Léon Bérard, Lyon, France \\ ${ }^{7}$ Aix-Marseille Université, Marseille, France \\ ${ }^{8}$ Service de Neurochirurgie, Hôpital La Timone, Assistance Publique-Hôpitaux de Marseille, Marseille, France \\ ${ }^{9}$ Service d'Oncologie et Hématologie Pédiatrique, Hôpital La Timone, Assistance Publique-Hôpitaux de Marseille, Marseille, \\ France \\ ${ }^{10}$ Service de Radiothérapie, Hôpital La Timone, Assistance Publique-Hôpitaux de Marseille, Marseille, France
}

Correspondence to: Gregorio J. Petrirena, email: gregorio.petrirena@ap-hm.fr

Keywords: sonic hedgehog medulloblastoma; vismodegib; temozolomide; smoothened mutation; PIK3CA mutation

Received: June 03, 2017 Accepted: November 01, $2017 \quad$ Published: January 03, 2018

Copyright: Petrirena et al. This is an open-access article distributed under the terms of the Creative Commons Attribution License 3.0 (CC BY 3.0), which permits unrestricted use, distribution, and reproduction in any medium, provided the original author and source are credited.

\section{ABSTRACT}

Background: Response to targeting and non-targeting agents is variable and molecular information remains poorly described in patients with recurrent sonichedgehog-driven medulloblastoma (SHH-MB).

Materials and Methods: Clinical and PET/CT findings during treatment with successive hedgehog antagonists and temozolomide monotherapies are described in a heavily pre-treated patient with recurrent extraneural metastases from PTCH1 mutated/ wild type smoothened (SMO) CNS SHH-MB. Molecular tests were prospectively performed in tissue from two extraneural sites at progression.

Results: Sustained clinical/metabolic response was obtained to vismodegib. At progression, itraconazole was ineffective, but salvage temozolomide treatment results in a response similar to vismodegib. At further progression, acquired SMO and PIK3CA mutations were identified in bone (G477L and H1047A, respectively) and epidural (L412P and H1065L, respectively) metastases. No response was observed with subsequent sonidegib treatment.

Conclusions: This is the first clinical report of recurrent extraneural PTCH1 mutated SHH-MB exhibiting: 1) a sustained response to vismodegib and temozolomide, and 2) inter-metastatic molecular heterogeneity and acquired SMO-G477L, SMOL412P, and PIK3CA-H1065L mutations at progression, highlighting the need for a multitarget treatment approach. 


\section{INTRODUCTION}

Medulloblastoma (MB) is the most common malignant pediatric brain tumor, with at least four major molecular subgroups identified. Sonic-hedgehog (SHH) subgroup MB (SHH-MB) comprises the majority of infant and adult MBs [1]. For patients with recurrent SHH-MB, survival is dismal [2]. Although disease recurrence is usually confined within the CNS, extraneural metastases may rarely develop [3-5].

Systemic SHH inhibitors, such as vismodegib and sonidegib, represent a therapeutic option for recurrent SHH-MB [6]; however, variable response rates have been reported [2], mostly due to the molecular heterogeneity among SHH-MBs [7]. Moreover, although the proof of principle of the $S M O$ mutation conferring acquired resistance to vismodegib was provided in a SHH-MB patient, molecular aberrations in relapsing SHH-MB remain poorly described in the clinic setting compared to preclinical models $[2,8-10]$. However, the limited impact of molecular profiling on the current management of advanced disease, makes performing invasive procedures required for tumor sampling and molecular testing difficult.

The aim of this case report was to describe: 1) the clinical/metabolic response to vismodegib and salvage treatment with temozolomide and other SHH antagonists in a patient with recurrent extraneural SHH-MB, and 2) the molecular profiling of the primary CNS tumor and extraneural metastases at disease progression.

\section{CASE REPORT}

A 16-year-old male was diagnosed with standard risk desmoplastic MB of the cerebellum in December 2008. He received bi-fractionated craniospinal irradiation (CSI; 36 Gy CSI in 36 fractions, with 68 Gy for boost on tumor bed in 68 fractions) according to the MSFOP 98 trial [11] resulting in complete response. For the isolated extraneural metastases of bone and bone marrow that occurred in November 2011, he received chemotherapy with etoposide, carboplatin, cisplatin, cyclophosphamide, irinotecan, and temozolomide, followed by intensive chemotherapy with busulfan/thiotepa and autologous stem cell transplantation. Maintenance with etoposide, celecoxib, cyclophosphamide, and temozolomide was delivered until December 2012, when a PET/CT and bone marrow examination showed complete response. In August 2014, left hip pain prompted a PET/CT scan that revealed a local hypermetabolic lesion, identified as necrotic tumor recurrence by biopsy. Focal radiotherapy with concomitant oral temozolomide allowed complete hip pain control. In January 2015, multifocal pain developed and a PET/CT scan revealed multiple hypermetabolic skeletal lesions of the spine, sternum, pelvis, and proximal extremities (Figures 1A and 2A). Retrospective immunohistochemical analysis of the primary CNS tumor showed the SHH-MB immunophenotype [12], which was further confirmed by retrospective CGH array and targeted next-generation sequencing showing chromosome $9 \mathrm{q}$ copy neutral-loss of heterozygosity and the PTCH1 mutation, respectively (Table 1, Figure 3). On 28 January, 2015, he was enrolled onto the NCT01601184 study and 150 mg PO once daily vismodegib monotherapy was started. His diffuse pain disappeared three weeks after treatment initiation; hence, morphine was discontinued. Whole body PET/CT scans performed in March and May 2015 revealed a partial metabolic response (data not shown), which was further confirmed in July 2015 (Figures 1B and 2B). Grade $1 \mathrm{cramp} /$ alopecia/dysgeusia and grade 2 diarrhea were observed under vismodegib without impacting his daily living. In October 2015, the back pain reappeared; a PET/CT scan revealed recurrent disease (Figures $1 \mathrm{C}$ and 2C), which was treated with $150 \mathrm{mg}$ twice daily itraconazole. The patient had a normal itraconazole serum level $(1673 \mathrm{ng} / \mathrm{ml}$; antifungal therapeutic range, $1000-4000 \mathrm{ng} / \mathrm{ml}$ ) on day 14 of treatment initiation. However, he had progressively increasing skeletal pain and serum C-reactive protein (CRP) levels. The PET/ CT scan performed five weeks after treatment initiation showed skeletal disease progression (Figures 1D and 2D). He received temozolomide (first cycle $150 \mathrm{mg} / \mathrm{m}^{2} /$ day then $200 \mathrm{mg} / \mathrm{m}^{2} /$ day) five days per month. Three weeks after the second cycle, pain began to improve and the elevated serum CRP level diminished. A PET/CT scan performed after four cycles of temozolomide showed a partial metabolic response while the patient was asymptomatic with almost normal serum CRP levels (Figures 1E and 2E). He remained asymptomatic and monthly temozolomide was continued until August 2016 when progressive multifocal pain reappeared and his CRP level increased. Multifocal skeletal recurrence was observed on a PET/CT scan (Figures $1 \mathrm{~F}$ and $2 \mathrm{~F}$ ) and the thoracic paravertebral hypermetabolic foci (Figure 4A) were confirmed as an epidural metastasis on MRI (Figure 4B). A sacral biopsy was performed for molecular analysis after obtaining the patient's consent (Figure 2F). On September 9, 2016, $400 \mathrm{mg}$ (oral suspension) once daily sonidegib was started. Ten days later he rapidly developed numbness in the lower trunk and extremities, paraparesis, and urinary retention requiring urgent neurosurgical evaluation. MRI showed thoracic epidural mass progression with increased spinal cord compression (Figure 4C), as well as a new epidural lesion at the 3rd lumbar vertebral level with incipient cauda equina compression (data not shown). Sonidegib was temporarily discontinued and emergency surgery performed, resulting in immediate neurological improvement and successful spinal cord decompression (Figure 4D). On postoperative Day 4, $800 \mathrm{mg}$ once daily Sonidegib was restarted. Focal radiotherapy consisting three fractions of 6 Gy and three fractions of 8 Gy was delivered every two days on the postoperative thoracic and 
lumbar extradural lesions, respectively. Pain temporarily improved and his CRP level almost normalized; however, on November 2, 2016, sonidegib was interrupted due to grade 4 serum creatine kinase (CK) elevation. While $400 \mathrm{mg}$ once daily sonidegib was restarted after CK normalization, vomiting precluded a good adherence thereafter. The patient experienced severe multifocal pain and increased serum CRP levels within three weeks and in December 2016, a PET/CT scan showed new extraneural lesions within and outside the skeleton. Comparative molecular analysis between the primary CNS tumor and relapsing bone and epidural metastases showed a similar PTCH1 mutated profile. However, acquired SMO (G477L and L412P) and PIK3CA (H1047A and H1065L) mutations with inter-tumoral heterogeneity were identified without evidence of SHH activation downstream of SMO or TP53 and MYC/MYCN aberrations (Table 1, Figure 3). The patient died of progressive disease four months later despite a new salvage regimen.

\section{DISCUSSION}

This case illustrates that recurrent extraneural metastatic SHH-MB is not an inevitable end-stage condition, and that even heavily pre-treated patients should be considered for targeted and non-targeted treatments.

Although molecular subtype data was not available in the largest reported series of extraneural metastatic MB [5], the correlation between desmoplastic histology and SHH activation [12] suggests that the majority of longterm survivors belong to the SHH-MB subgroup [5]. Similar to our case, most of desmoplastic MB patients only received CSI as the initial treatment, raising the question of the validity of systematic chemotherapy to eradicate subclinical metastatic extraneural disease in this MB subgroup.

Sustained objective response with an acceptable toxicity profile to vismodegib was observed in our case with PTCH1 mutation-driven SHH-MB, supporting the idea that isolated mutations upstream of SMO without downstream activating aberrations predict the response to SMO inhibitors [7]. Similarly, in the largest clinical trial of SMO inhibitors for recurrent SHH-MB, somatic loss-ofheterozygosity of $\mathrm{PTCH} 1$ was associated with prolonged progression-free survival, and loss-of-function PTCH1 mutations were only found among responders [2]. The role of vismodegib as a maintenance therapy after traditional chemotherapy for newly diagnosed SHH-MB is currently under investigation (NCT01878617).

It is important to note that, in our case, tumor profiling was unknown at the time of vismodegib initiation. However, the sustained response to vismodegib strongly suggests the maintenance of the homozygous PTCH1 mutation as the predominant oncodriver at this time. The presumed genomic stability during the first six years of multitreated disease could be partly related to the lack of TP53 mutation in the primary tumor [13, 14], which is otherwise consistent with the prolonged survival of our patient. In contrast, a recent publication showed a poor overlap of genetic events in recurrent murine SHH-MB after "humanized" in vivo therapy with those in matched murine diagnostic samples [15]. Similarly, substantial genetic divergence was observed between human diagnostic and recurrent $\mathrm{MB}$ after standard therapy. Interestingly, one SHH-MB patient with a clonally dominant homozygous $\mathrm{PTCH} 1$ driver mutation in the primary tumor exhibited a complete switch in the oncodriver mutation in the recurrent tumor (derived from ancestral lineage with wild-type chro9q heterozygosity). Thus, the authors emphasized the importance of performing rebiopsies and profiling the recurrent compartments to more appropriately direct subsequent therapies [15].

Unfortunately, acquired resistance to SMO antagonists is uniformly reported in responder SHH-MB patients $[2,4]$, as illustrated in our case. In accordance with a recent study [16], the two metastatic compartments examined in our case retained the same molecular affiliation as the primary CNS tumor; however, acquired mutations were also found in both sites with an intertumoral molecular heterogeneity profile.

The spectrum of mutant SMO conferring $\mathrm{SHH}$ inhibitor resistance has rapidly expanded in recent years, after the first mutation, $\mathrm{D} 473 \mathrm{H}$, was identified in a metastatic SHH-MB patient exhibiting a dramatic but only transient response to vismodegib $[3,8]$. Recent clinical studies in basal cell carcinoma (BCC), a frequent $\mathrm{SHH}-$ driven tumor, showed that SMO genetic alterations include ligand binding pocket (LBP) mutations, which define sites of inhibitor binding, as well as mutations in structural pivot regions conferring constitutive receptor activity and drug resistance. These topographically different $S M O$ mutations may confer both intrinsic and acquired resistance to $\mathrm{SHH}$ inhibitors $[17,18]$.

The SMO-G477L mutation identified in the relapsing sacral bone metastasis of our patient was recently described among the SMO-LBP mutants in vismodegib-resistant BCC [17]. Atwood et al. found that this mutant exhibited a high level of drug resistance (the vismodegib half-maximal inhibitory concentration $\left[\mathrm{IC}_{50}\right]$ was 40-fold higher compared with $S M O$ wild type), without significantly altering basal SHH pathway activity. Progression of the sacral lesion under vismodegib after a transient partial metabolic response (Figure 2) suggests that expansion of SMO-G477L mutant subclones most likely occurred during vismodegib therapy.

The SMO-L412P mutation was identified in the epidural metastases detected after progression under temozolomide. This mutation which is located outside the LBP of SMO and previously reported as an oncogenic driver, was recently identified in pre- and post-treatment samples of a patient with metastatic BCC who initially 
Table 1: Molecular analyses of primary CNS tumor and two extraneural metastases after progression to vismodegib and temozolomide monotherapies

\begin{tabular}{|c|c|c|c|c|c|c|c|c|}
\hline & РТCH 1 & SMO & $\boldsymbol{S U F U}$ & PIK3CA & TP53 & GLI 2 & $M Y C / M Y C N$ & $\begin{array}{l}M G M T \\
\text { promoter }\end{array}$ \\
\hline $\begin{array}{l}\text { Primary CNS } \\
\text { tumor } \\
(19 / 12 / 2008)\end{array}$ & $\begin{array}{l}\text { p.Gln } 160^{*} \\
\text { hmz mut }\end{array}$ & wt & wt & wt & wt & n-amp & n-amp/n-amp & unmethylated \\
\hline $\begin{array}{l}\text { Bone } \\
\text { metastasis } \\
(31 / 08 / 2016)\end{array}$ & $\begin{array}{l}\text { p.Gln } 160^{*} \\
\text { hmz mut }\end{array}$ & $\begin{array}{l}\text { p.Gln477Lys } \\
\text { mut }\end{array}$ & wt & $\begin{array}{l}\text { p.His1047Arg } \\
\text { mut }\end{array}$ & wt & n-amp & n-amp/n-amp & NA \\
\hline $\begin{array}{l}\text { Epidural } \\
\text { metastasis } \\
(21 / 09 / 2016)\end{array}$ & $\begin{array}{l}\text { p.Gln } 160^{*} \\
\text { hmz mut }\end{array}$ & $\begin{array}{l}\text { p.Leu412Phe } \\
\text { mut }\end{array}$ & wt & $\begin{array}{l}\text { p.His 1065Leu } \\
\text { mut }\end{array}$ & wt & n-amp & n-amp/n-amp & unmethylated \\
\hline
\end{tabular}

Abbreviations: hmz, hemizygous; mut, mutation; wt, wild type; n-amp, non-amplified; NA, not available.

responded to vismodegib. The authors speculated that the acquired loss of the PTCH1 mutation in the setting of this oncogenic mutation probably promoted tumor regrowth under vismodegib in their patient [18].

Hyperactivation of phosphatidylinositol 3-kinase (PI3K) signaling cascades is one of the most common events in human cancers, often via PIK3CA hotspot missense mutations [19]. Recurrent PIK3CA, PTEN, and $P I K 3 C 2 G$ mutations were identified in the largest genome sequencing series of newly diagnosed SHH-MB patients; the vast majority of lesions with immunostaining evidence of PI3K pathway activation were from adult patients, and immunostaining positivity was strongly associated with poor outcome in this population [7]. Moreover, Robinson et al. also identified PIK3 and PTEN mutations in the SHH-MB subset that did not respond to vismodegib [2].

In the present case, however, no evidence of PI3K pathway activation was observed in the primary CNS tumor. Instead, $P I K 3 C A$ mutations were identified in the setting of advanced extraneural relapsing disease, suggesting a potential role in $\mathrm{MB}$ progression rather than in tumor initiation, as suggested by preclinical models [20]. The H1047A mutation, which is the most frequent activating aberration of the PIK3CA gene encoding the p110 $\alpha$ catalytic subunit (exon 20) of the class I PI3Ks in human tumors, was identified in the sacral bone metastasis. Interestingly, the mutation found in the epidural metastasis at 1065 amino acid position of exon 20 has not been previously described in human SHH-MB. This mutation considered infrequent but with a high pathogenic score according to the COSMIC database (http://www.sanger. ac.uk/genetics/CGP/cosmic), has been reported in deeply invasive endometrial carcinoma and salivary gland tumors, and invasive lobular breast cancer [21]. Additional data suggest that this variation could be pathogenic: both the nucleotide (c.3194) and the amino acid (p.1065) are highly
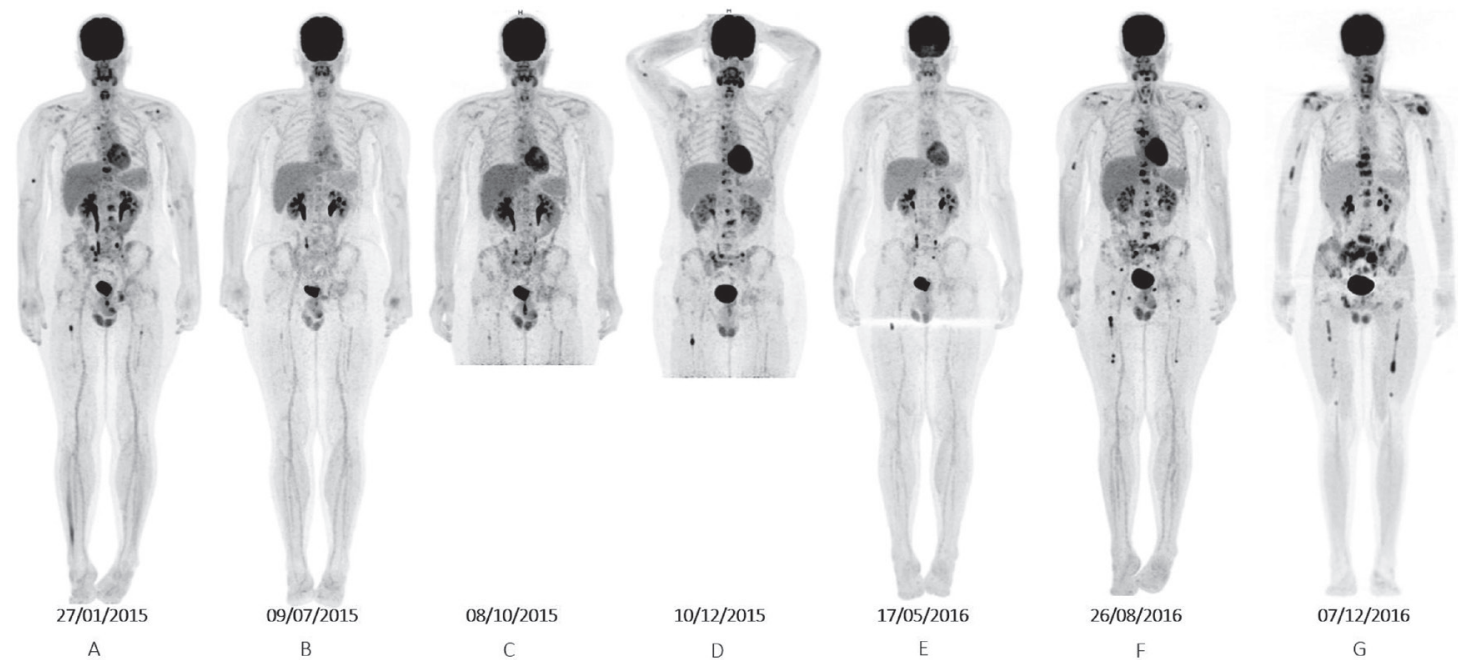

Figure 1: Whole body projections from $\mathrm{F}^{18}$-fluorodeoxyglucose PET scans showing (A) baseline examination before vismodegib, (B) partial response to vismodegib, (C) disease progression under vismodegib, (D) further progression under itraconazole, (E) partial response to temozolomide, $(\mathbf{F})$ progression under temozolomide, and $(\mathbf{G})$ progression after sonidegib with response in 6th thoracic and 3rd lumbar locally treated lesions. 


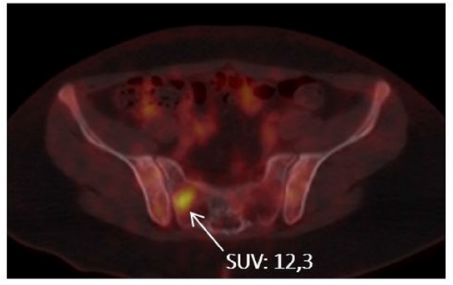

A

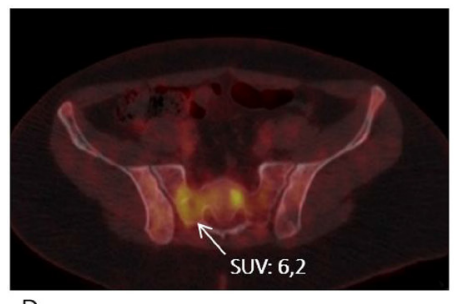

D

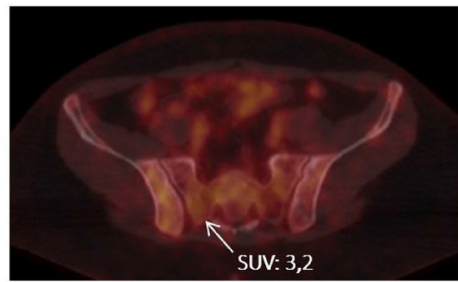

B

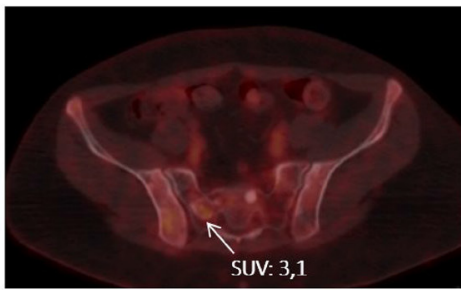

$E$

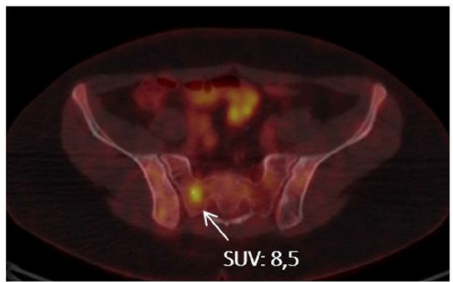

C

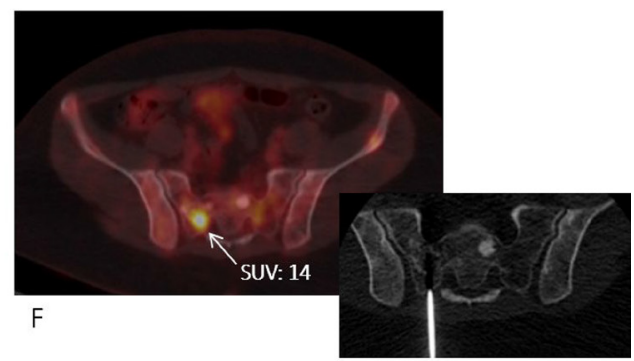

Figure 2: Axial $\mathrm{F}^{18}$-fluorodeoxyglucose PET/CT images at the pelvic level showing the right sacral alae lesion (arrow) chosen as a target for molecular analyses after progression to temozolomide. (A) Before vismodegib monotherapy, (B) partial response to vismodegib, (C) disease progression under vismodegib, (D) further lesion size progression under itraconazole, (E) partial response to temozolomide, and (F) progression under temozolomide when the CT scan-guided biopsy was performed (F').
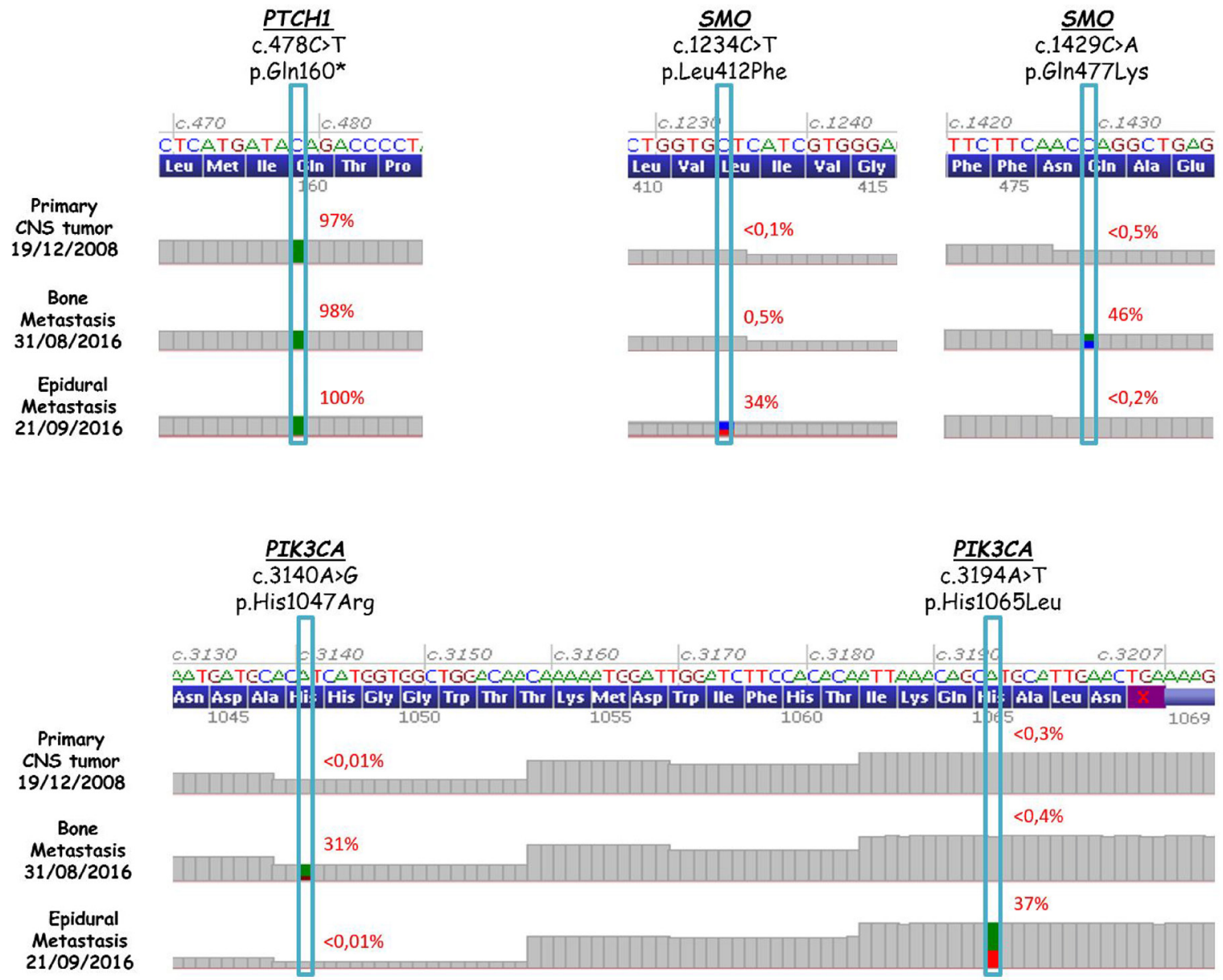

Figure 3: PTCH1 (top-left), SMO (top-right), and PIK3CA (bottom) sequence analysis in the primary CNS tumor and two extraneural metastases after progression to vismodegib and temozolomide. 
conserved, the biochemical distance between histidine and leucine is significant, and this variation is located in the catalytic domain of the protein.

The precise mechanism by which PIK3CA and SMO mutations interplayed to promote tumor progression in our patient is unknown. Previously, Riobó et al. demonstrated in several experimental systems that activation of PI3K/ Akt increases sonic-hedgehog-induced GLI transcriptional activity by inhibiting PKA-dependent GLI2 inactivation [22]. Cumulative data indicate that SMO-independent hedgehog signaling, namely non-canonical hedgehog signaling, plays an essential role in cancer through activation of GLI as the output for numerous other oncogenic pathway [23]. In line with this, dual PI3K/ mTOR inhibition was recently found to exert potent antineoplastic effects and to decrease nuclear localization of GLI, as well as GLI target gene expression in DAOY and D556 MB cell lines [24]. Accordingly, restored canonical SHH pathway via SMO mutations leading to the evasion of SMO antagonists probably synergized with enhanced PI3K signaling to promote GLI activation in our case. However, it is speculative and alternative pathway crosstalk leading to disease progression cannot be excluded.

Objective sustained response was also observed to temozolomide. Similar results have been reported for both extraneural and CNS relapsing MB; however, the molecular subtyping was not provided [25-27]. To our knowledge, the present case is the first report of successful temozolomide salvage treatment after vismodegib progression, suggesting that acquired resistance to vismodegib does not necessarily promote the development of an alkylating resistance phenotype. Of note, the objective therapeutic response was observed despite an unmethylated MGMT promoter. This is in accordance with a recent publication showing that the expression of MGMT is not predictive of intrinsic alkylating agent resistance in $\mathrm{MB}$ [28]. Whether a more prolonged response was possible with combined vismodegib and temozolomide therapy rather than monotherapies in our patient is unclear; the ongoing trial (NCT01601184) is addressing this question.

At the time of progression to vismodegib, we have attempted hedgehog pathway inhibition differently. In a mouse allograft model, itraconazole inhibited SHH pathway activity and MB growth at serum levels comparable to those in patients undergoing antifungal therapy, presumably by binding to a site distinct from that of cyclopamine [29]. The authors subsequently showed that itraconazole prolonged the survival of mice with intracranial vismodegib-resistant tumors harboring D477G mice mutation, homologous to the D473H human mutation [30]. However, no therapeutic response was observed in our patient despite adequate serum levels, possibly because itraconazole acts as a partial SMO mutant antagonist, with higher doses being required to overcome the elevated $\mathrm{IC}_{50}$ and resistance in human vismodegib-induced SMO mutants. It might also reflect limitations of preclinical models in reproducing real clinical scenarios and/or that alternative oncodrivers, such as PIK3 pathway activation, were already present. To date, no clinical experience concerning the use of itraconazole in vismodegib-naïve or resistant SHH-MB has been reported. In a recent exploratory phase II trial,
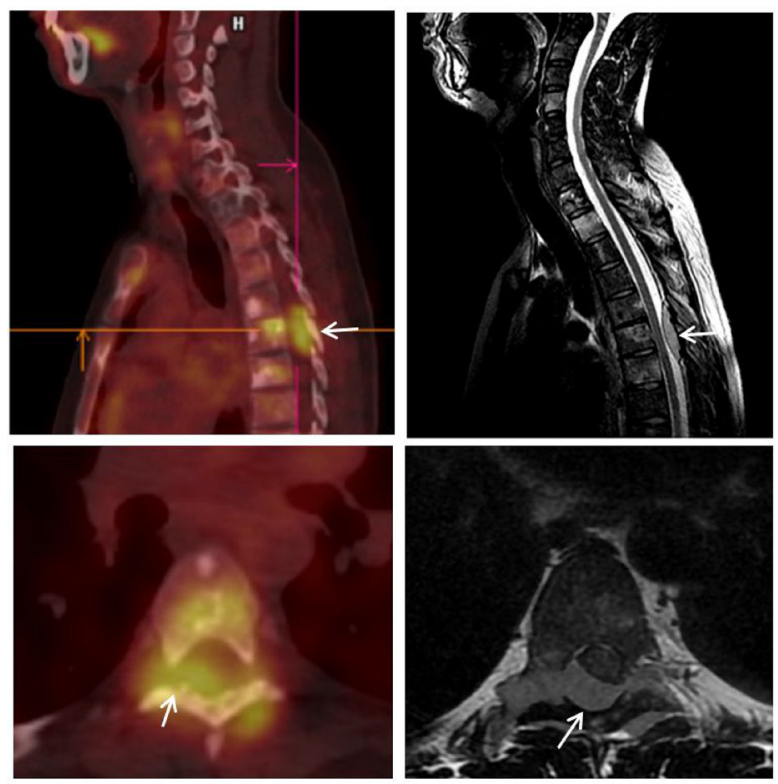

A

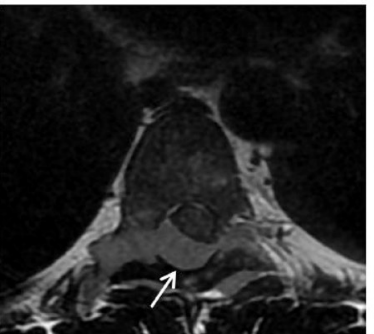

B
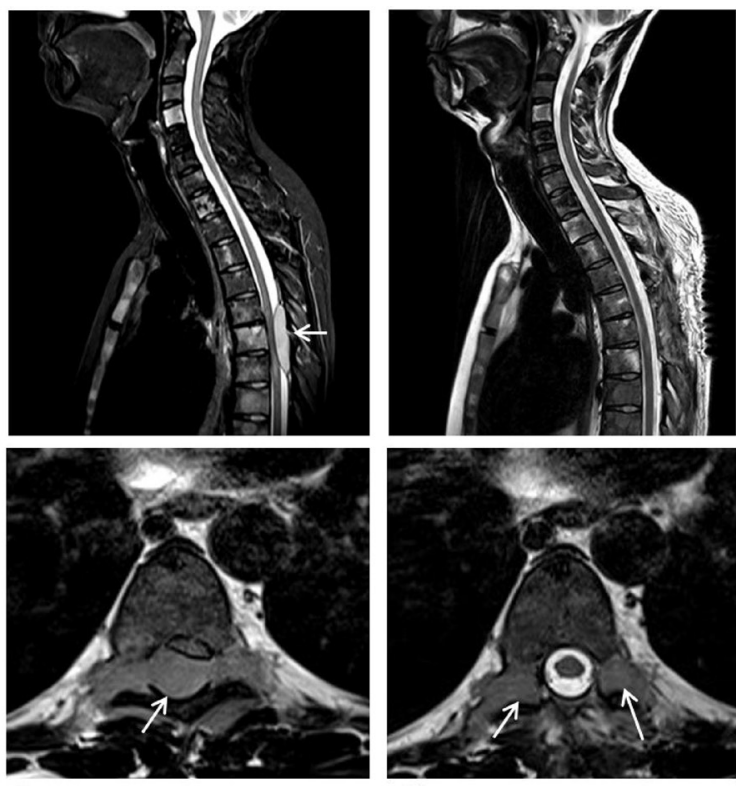

C

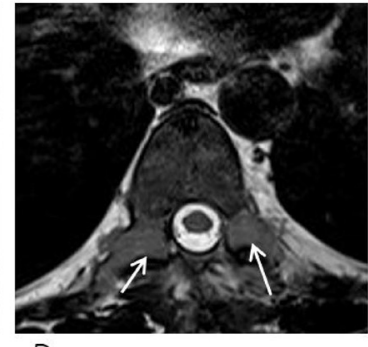

D

Figure 4: (A) Thoracic epidural metastasis (arrow) detected on PET/CT at progression under temozolomide. T2-weighted MRI scan of the spine at (B) baseline, $(\mathbf{C})$ ten days after starting sonidegib showing tumor progression, and (D) after surgical decompression (raw sagittal and axial images on top and bottom, respectively). 
itraconazole showed anti-BCC activity in vismodegibnaïve patients. However, similar to our case, the three patients with vismodegib-resistant BCC receiving 200 mg twice daily itraconazole experienced progression during therapy [31].

In a phase I trial, sonidegib exhibited an acceptable safety profile, exposure-dependent reduction in GLI1 mRNA expression, and clinically relevant antitumor effect in patients with relapsed SHH-MB [32]. In a more recent I-II study, four patients (two children and two adults) among 10 with relapsing SHH-MB achieved complete response under sonidegib, but the correlation between response and hedgehog pathway alterations could not be evaluated due to insufficient patient material [33].

Nevertheless, the potential usefulness of sonidegib in SHH-MB patients with acquired resistance to vismodegib has not been previously reported. In a recent clinical study, patients with advanced BCC who developed resistant to vismodegib did not respond to sonidegib, yet one patient with a baseline SMO-D473 mutation had stable disease for 58 weeks, presumably due to intra-tumoral heterogeneity [34]. Early treatment discontinuation due to adverse events makes analysis complex in our patient. Nevertheless, severe progression three weeks after treatment interruption despite the relatively long half-life of sonidegib [32] strongly suggests limited antitumoral activity. Of note, the SMO-G477L mutation, which is known to confer resistance to sonidegib in BCC [34], and PI3K molecular aberrations were already present at the time of treatment initiation.

The main limitation of this report is the lack of molecular information at the time of each new therapeutic intervention. However, this reflects clinical settings and does not dramatically hamper, in our opinion, the relevance of our findings.

\section{CONCLUSIONS}

Recurrent extraneural PTCH1 mutated SHH-MB does not necessarily represent an end-stage condition. Vismodegib and temozolomide monotherapies allowed sustained responses with good quality daily living in our heavily pre-treated patient. However, salvage therapy with other $\mathrm{SHH}$ inhibitors after acquired resistance to vismodegib did not provide clear benefit.

Inter-metastatic molecular heterogeneity observed at disease progression suggests that spatially variable subclone selection occurred during treatment. SMO-G477L, SMOL412P, and PIK3CA-H1065L mutations are identified for the first time in a recurrent $\mathrm{SHH}-\mathrm{MB}$ patient. These features and the bona fide oncogenic mutant PIK3CA-H1047A identified in our patient highlight the cooperating role of $\mathrm{SHH}$ and PIK3 pathways in the development of acquired resistance and disease progression in SHH-MB. Therefore, as supported by preclinical studies [10] multitarget therapy may be a more adequate strategy to treat this aggressive cancer.

\section{Abbreviations}

MB: medulloblastoma; SHH: sonic-hedgehog signaling pathway; SHH-MB: sonic hedgehog-driven medulloblastoma ; PTCH1: gene encoding patched homologue 1, PTCH1; SMO: gene encoding smoothened receptor, SMO; PET/CT: positron emission tomography/ computed tomography; CNS: central nervous system; CSI: craniospinal irradiation; CRP: serum C-reactive protein; MRI: magnetic resonance imaging; $\mathrm{CK}$ : creatine kinase; $M G M T$ : gene encoding methylguanine methyltransferase, MGMT; BCC: basal cell carcinoma; LBP: ligand binding pocket; $\mathrm{IC}_{50 \text { : }}$ half-maximal inhibitory concentration ; PIK3: phosphatidylinositol 3-kinase; COSMIC: Catalogue of Somatic Mutations in Cancer.

\section{Author contributions}

O.C. and L.P. contributed equally to this work.

\section{ACKNOWLEDGMENTS}

We thank Dr Christophe Chagnaud for tissue sampling of the bone metastasis used for molecular analysis.

\section{CONFLICTS OF INTEREST}

No potential conflicts of interest are disclosed. All the authors read and approved the final version of the manuscript prior to submission.

\section{FUNDING}

We thank the Association pour la Recherche sur les Tumeurs Cérébrales Sud and the Ligue Contre le Cancer Corse-du-Sud for their financial support.

\section{REFERENCES}

1. Northcott PA, Korshunov A, Pfister SM, Taylor MD. The clinical implications of medulloblastoma subgroups. Nat Rev Neurol. 2012; 8:340-51. https://doi.org/10.1038/ nrneurol.2012.78.

2. Robinson GW, Orr BA, Wu G, Gururangan S, Lin T, Qaddoumi I, Packer RJ, Goldman S, Prados MD, Desjardins A, Chintagumpala M, Takebe N, Kaste SC, et al. Vismodegib Exerts Targeted Efficacy Against Recurrent Sonic Hedgehog-Subgroup Medulloblastoma: Results From Phase II Pediatric Brain Tumor Consortium Studies PBTC-025B and PBTC-032. J Clin Oncol Off J Am Soc Clin Oncol. 2015; 33:2646-54. https://doi.org/10.1200/ JCO.2014.60.1591.

3. Rudin CM, Hann CL, Laterra J, Yauch RL, Callahan CA, Fu L, Holcomb T, Stinson J, Gould SE, Coleman B, 
LoRusso PM, Von Hoff DD, de Sauvage FJ, et al. Treatment of medulloblastoma with hedgehog pathway inhibitor GDC-0449. N Engl J Med. 2009; 361:1173-8. https://doi. org/10.1056/NEJMoa0902903.

4. Asklund T, Henriksson R, Axelsson J, Bergström Å, Kasper M, Ögren M, Toftgård R, Riklund KÅ. Early and persisting response to vismodegib in a patient with bone metastasizing medulloblastoma. Acta Oncol Stockh Swed. 2013; 52:8626. https://doi.org/10.3109/0284186X.2012.724537.

5. Young RJ, Khakoo Y, Yhu S, Wolden S, De Braganca KC, Gilheeney SW, Dunkel IJ. Extraneural metastases of medulloblastoma: desmoplastic variants may have prolonged survival. Pediatr Blood Cancer. 2015; 62:611-5. https://doi.org/10.1002/pbc.25354.

6. Brandes AA, Bartolotti M, Marucci G, Ghimenton C, Agati R, Fioravanti A, Mascarin M, Volpin L, Ammannati F, Masotto B, Gardiman MP, De Biase D, Tallini G, et al. New perspectives in the treatment of adult medulloblastoma in the era of molecular oncology. Crit Rev Oncol Hematol. 2015; 94:348-59. https://doi.org/10.1016/j. critrevonc.2014.12.016.

7. Kool M, Jones DT, Jäger N, Northcott PA, Pugh TJ, Hovestadt V, Piro RM, Esparza LA, Markant SL, Remke M, Milde T, Bourdeaut F, Ryzhova M, et al, and ICGC PedBrain Tumor Project. Genome sequencing of $\mathrm{SHH}$ medulloblastoma predicts genotype-related response to smoothened inhibition. Cancer Cell. 2014; 25:393-405. https://doi.org/10.1016/j.ccr.2014.02.004.

8. Yauch RL, Dijkgraaf GJ, Alicke B, Januario T, Ahn CP, Holcomb T, Pujara K, Stinson J, Callahan CA, Tang T, Bazan JF, Kan Z, Seshagiri S, et al. Smoothened mutation confers resistance to a Hedgehog pathway inhibitor in medulloblastoma. Science. 2009; 326:572-4. https://doi. org/10.1126/science.1179386.

9. Dijkgraaf GJP, Alicke B, Weinmann L, Januario T, West K, Modrusan Z, Burdick D, Goldsmith R, Robarge K, Sutherlin D, Scales SJ, Gould SE, Yauch RL, et al. Small molecule inhibition of GDC-0449 refractory smoothened mutants and downstream mechanisms of drug resistance. Cancer Res. 2011; 71:435-44. https://doi.org/10.1158/00085472.CAN-10-2876.

10. Buonamici S, Williams J, Morrissey M, Wang A, Guo R, Vattay A, Hsiao K, Yuan J, Green J, Ospina B, Yu Q, Ostrom L, Fordjour P, et al. Interfering with resistance to smoothened antagonists by inhibition of the PI3K pathway in medulloblastoma. Sci Transl Med. 2010; 2:51ra70. https://doi.org/10.1126/scitranslmed.3001599.

11. Carrie C, Grill J, Figarella-Branger D, Bernier V, Padovani L, Habrand JL, Benhassel M, Mege M, Mahé M, Quetin P, Maire JP, Baron MH, Clavere P, et al. Online quality control, hyperfractionated radiotherapy alone and reduced boost volume for standard risk medulloblastoma: longterm results of MSFOP 98. J Clin Oncol Off J Am Soc Clin Oncol. 2009; 27:1879-83. https://doi.org/10.1200/ JCO.2008.18.6437.
12. Ellison DW, Dalton J, Kocak M, Nicholson SL, Fraga C, Neale G, Kenney AM, Brat DJ, Perry A, Yong WH, Taylor RE, Bailey S, Clifford SC, et al. Medulloblastoma: clinicopathological correlates of SHH, WNT, and non-SHH/ WNT molecular subgroups. Acta Neuropathol (Berl). 2011; 121:381-96. https://doi.org/10.1007/s00401-011-0800-8.

13. Rausch T, Jones DTW, Zapatka M, Stütz AM, Zichner T, Weischenfeldt J, Jäger N, Remke M, Shih D, Northcott PA, Pfaff E, Tica J, Wang Q, et al. Genome sequencing of pediatric medulloblastoma links catastrophic DNA rearrangements with TP53 mutations. Cell. 2012; 148:5971. https://doi.org/10.1016/j.cell.2011.12.013.

14. Zhukova N, Ramaswamy V, Remke M, Pfaff E, Shih DJH, Martin DC, Castelo-Branco P, Baskin B, Ray PN, Bouffet E, von Bueren AO, Jones DTW, Northcott PA, et al. Subgroup-specific prognostic implications of TP53 mutation in medulloblastoma. J Clin Oncol Off J Am Soc Clin Oncol. 2013; 31:2927-35. https://doi.org/10.1200/ JCO.2012.48.5052.

15. Morrissy AS, Garzia L, Shih DJ, Zuyderduyn S, Huang X, Skowron P, Remke M, Cavalli FM, Ramaswamy V, Lindsay PE, Jelveh S, Donovan LK, Wang X, et al. Divergent clonal selection dominates medulloblastoma at recurrence. Nature. 2016; 529:351-7. https://doi.org/10.1038/nature16478.

16. Wang X, Dubuc AM, Ramaswamy V, Mack S, Gendoo DM, Remke M, Wu X, Garzia L, Luu B, Cavalli F, Peacock J, López B, Skowron P, et al. Medulloblastoma subgroups remain stable across primary and metastatic compartments. Acta Neuropathol (Berl). 2015; 129:449-57. https://doi. org/10.1007/s00401-015-1389-0.

17. Atwood SX, Sarin KY, Whitson RJ, Li JR, Kim G, Rezaee M, Ally MS, Kim J, Yao C, Chang ALS, Oro AE, Tang JY. Smoothened variants explain the majority of drug resistance in basal cell carcinoma. Cancer Cell. 2015; 27:342-53. https://doi.org/10.1016/j.ccell.2015.02.002.

18. Sharpe HJ, Pau G, Dijkgraaf GJ, Basset-Seguin N, Modrusan Z, Januario T, Tsui V, Durham AB, Dlugosz AA, Haverty PM, Bourgon R, Tang JY, Sarin KY, et al. Genomic analysis of smoothened inhibitor resistance in basal cell carcinoma. Cancer Cell. 2015; 27:327-41. https://doi. org/10.1016/j.ccell.2015.02.001.

19. Samuels Y, Wang Z, Bardelli A, Silliman N, Ptak J, Szabo S, Yan H, Gazdar A, Powell SM, Riggins GJ, Willson JKV, Markowitz S, Kinzler KW, et al. High frequency of mutations of the PIK3CA gene in human cancers. Science. 2004; 304:554. https://doi.org/10.1126/science.1096502.

20. Robinson G, Parker M, Kranenburg TA, Lu C, Chen X, Ding L, Phoenix TN, Hedlund E, Wei L, Zhu X, Chalhoub $\mathrm{N}$, Baker SJ, Huether R, et al. Novel mutations target distinct subgroups of medulloblastoma. Nature. 2012; 488:43-8. https://doi.org/10.1038/nature11213.

21. Ciriello G, Gatza ML, Beck AH, Wilkerson MD, Rhie SK, Pastore A, Zhang H, McLellan M, Yau C, Kandoth C, Bowlby R, Shen H, Hayat S, et al, and TCGA Research Network. Comprehensive Molecular Portraits of Invasive 
Lobular Breast Cancer. Cell. 2015; 163:506-19. https://doi. org/10.1016/j.cell.2015.09.033.

22. Riobó NA, Lu K, Ai X, Haines GM, Emerson CP Jr. Phosphoinositide 3-kinase and Akt are essential for Sonic Hedgehog signaling. Proc Natl Acad Sci USA. 2006; 103:4505-10.

23. Gu D, Xie J. Non-Canonical Hh Signaling in Cancer-Current Understanding and Future Directions. Cancers (Basel). 2015; 7:1684-98. https://doi.org/10.3390/cancers7030857.

24. Clymer J, Eckerd F, Bell J, Lulla R, Goldman S, Platanias L. Platanias 1. Medu-44. Targeting shh signaling via pi3k/ mtor inhibition in medulloblastoma and ewing sarcoma. Neuro-oncol. 2017; 19:iv47-47.

25. O'Reilly SM, Newlands ES, Glaser MG, Brampton M, Rice-Edwards JM, Illingworth RD, Richards PG, Kennard C, Colquhoun IR, Lewis P, Stevens MFG. Temozolomide: a new oral cytotoxic chemotherapeutic agent with promising activity against primary brain tumours. Eur J Cancer. 1993; 29A:940-42.

26. Durando $\mathrm{X}$, Thivat E, Gilliot O, Irthum B, Verrelle P, Vincent C, Bay JO. Temozolomide treatment of an adult with a relapsing medulloblastoma. Cancer Invest. 2007; 25:470-5. https://doi.org/10.1080/07357900701518164.

27. Cefalo G, Massimino M, Ruggiero A, Barone G, Ridola V, Spreafico F, Potepan P, Abate ME, Mascarin M, Garrè ML, Perilongo G, Madon E, Colosimo C, Riccardi R. Temozolomide is an active agent in children with recurrent medulloblastoma/primitive neuroectodermal tumor: an Italian multi-institutional phase II trial. Neuro-oncol. 2014; 16:748-53.

28. Faoro D, von Bueren AO, Shalaby T, Sciuscio D, Hürlimann ML, Arnold L, Gerber NU, Haybaeck J, Mittelbronn M, Rutkowski S, Hegi M, Grotzer MA. Expression of $\mathrm{O}^{6}$ methylguanine-DNA methyltransferase in childhood medulloblastoma. J Neurooncol. 2011; 103:59-69. https:// doi.org/10.1007/s11060-010-0366-7.

29. Kim J, Tang JY, Gong R, Kim J, Lee JJ, Clemons KV, Chong CR, Chang KS, Fereshteh M, Gardner D, Reya T,
Liu JO, Epstein EH, et al. Itraconazole, a commonly used antifungal that inhibits Hedgehog pathway activity and cancer growth. Cancer Cell. 2010; 17:388-99. https://doi. org/10.1016/j.ccr.2010.02.027.

30. Kim J, Aftab BT, Tang JY, Kim D, Lee AH, Rezaee M, Kim J, Chen B, King EM, Borodovsky A, Riggins GJ, Epstein EH, Beachy PA, et al. Itraconazole and arsenic trioxide inhibit Hedgehog pathway activation and tumor growth associated with acquired resistance to smoothened antagonists. Cancer Cell. 2013; 23:23-34. https://doi. org/10.1016/j.ccr.2012.11.017.

31. Kim DJ, Kim J, Spaunhurst K, Montoya J, Khodosh R, Chandra K, Fu T, Gilliam A, Molgo M, Beachy PA, Tang JY. Open-label, exploratory phase II trial of oral itraconazole for the treatment of basal cell carcinoma. J Clin Oncol. 2014; 32:745-51. https://doi.org/10.1200/ JCO.2013.49.9525.

32. Rodon J, Tawbi HA, Thomas AL, Stoller RG, Turtschi CP, Baselga J, Sarantopoulos J, Mahalingam D, Shou Y, Moles MA, Yang L, Granvil C, Hurh E, et al. A phase I, multicenter, open-label, first-in-human, dose-escalation study of the oral smoothened inhibitor Sonidegib (LDE225) in patients with advanced solid tumors. Clin Cancer Res. 2014; 20:1900-09. https://doi.org/10.1158/1078-0432.CCR13-1710.

33. Kieran MW, Chisholm J, Casanova M, Brandes AA, Aerts I, Bouffet E, Bailey S, Leary S, MacDonald TJ, Mechinaud F, Cohen KJ, Riccardi R, Mason W, et al. Phase I study of oral sonidegib (LDE225) in pediatric brain and solid tumors and a phase II study in children and adults with relapsed medulloblastoma. Neuro-oncol. 2017; 19:1542-52. https:// doi.org/10.1093/neuonc/nox109.

34. Danial C, Sarin KY, Oro AE, Chang AL. An InvestigatorInitiated Open-Label Trial of Sonidegib in Advanced Basal Cell Carcinoma Patients Resistant to Vismodegib. Clin Cancer Res. 2016; 22:1325-29. https://doi. org/10.1158/1078-0432.CCR-15-1588. 